\title{
PIERRE MASSON, André Gide \& Marcel Proust. À la recherche de l'amitié
}

\section{Monia Mezzetti}

\section{(2) OpenEdition}

\section{Journals}

\section{Edizione digitale}

URL: https://journals.openedition.org/studifrancesi/44188

DOI: 10.4000/studifrancesi.44188

ISSN: 2427-5856

\section{Editore}

Rosenberg \& Sellier

\section{Edizione cartacea}

Data di pubblicazione: 1 juin 2021

Paginazione: 241

ISSN: 0039-2944

\section{Notizia bibliografica digitale}

Monia Mezzetti, «PIERRE MASSON, André Gide \& Marcel Proust. À la recherche de l'amitié», Studi Francesi

[Online], 193 (LXV | I) | 2021, online dal 01 juillet 2021, consultato il 15 octobre 2022. URL: http:// journals.openedition.org/studifrancesi/44188 ; DOI: https://doi.org/10.4000/studifrancesi.44188

Questo documento è stato generato automaticamente il 15 octobre 2022.

\section{(c) (†) $\odot$}

Creative Commons - Attribuzione - Non commerciale - Non opere derivate 4.0 Internazionale - CC BY NC-ND 4.0

https://creativecommons.org/licenses/by-nc-nd/4.0/ 


\title{
PIERRE MASSON, André Gide \& Marcel Proust. À la recherche de l'amitié
}

\author{
Monia Mezzetti
}

\section{NOTIZIA}

PIERRE MASSON, André Gide \& Marcel Proust. À la recherche de l'amitié, Lyon, Presses universitaires de Lyon, 2020, $140 \mathrm{pp}$.

1 Pierre Masson, professore emerito dell'Università di Nantes e presidente dell'Association des amis d'André Gide, già curatore degli ultimi quattro volumi della «Bibliothèque de la Pléiade» dedicati all'opera del grande romanziere francese, firma questo saggio che si contraddistingue tanto per il ricorso a una vasta documentazione di prima mano, quale è la corrispondenza tra Gide e Proust, quanto per il rigore dell'analisi, che si rispecchia perfino nella progettazione stessa dei capitoli, dedicati alternativamente all'uno e all'altro autore. L'interesse del volume non deriva soltanto dalla sua gradevolezza e dalla serietà del percorso di ricerca, ma anche dalla tesi che ne discende. L'A. corregge infatti la tesi dominante, in base alla quale i rapporti tra Gide e Proust sarebbero stati contrassegnati essenzialmente dall'inimicizia, a sua volta scaturita dal risentimento del secondo nei confronti del primo per aver rifiutato, in qualità di direttore della "Nouvelle revue française", il manoscritto all'epoca intitolato Le temps perdu; un rifiuto, questo, di cui Gide ebbe modo di pentirsi e che fu per lui fonte di un autentico senso di rimorso. Lo studioso dimostra come le conseguenze erroneamente amplificate di questo episodio abbiano a lungo impedito di conoscere il legame intenso e talvolta contraddittorio instauratosi tra Gide e Proust e poi a lungo mantenuto fino alla scomparsa prematura dell'autore della Recherche.

2 La monografia esplora quindi un campo peculiare, quello del dialogo, difficile ma ugualmente cercato, tra due intellettuali profondamente diversi per temperamento, per estrazione sociale, per formazione, per concezione della letteratura e, non ultimo, per atteggiamento nei confronti del proprio orientamento sessuale. Su questi aspetti si 
interrogano quindi i sedici capitoli del libro, all'interno dei quali si dà conto del notoriamente difficile rapporto coniugale di Gide con Madeleine, della liaison con Marc Allégret, ma anche dei suoi contatti con Oscar Wilde. Quanto al dialogo con Proust, viene messo in evidenza come questo sia stato spesso affidato al canale epistolare, data la difficoltà per i due uomini di incontrarsi, e come esso fosse indicativo di un'intesa non scontata. Su questo punto, la lettura di Pierre Masson diverge radicalmente da quella prevalente, imperniata invece sull'idea di un'irriducibile distanza tra Gide e Proust. Per Jean-Yves Tadié (Marcel Proust, 2007), ad esempio, «il n'y aura entre eux aucune affection profonde, aucune admiration véritable. Ce qu'écrit Gide n'intéresse pas Proust. Le premier constate l'existence de La Recherche comme celle du Mont Blanc» (p. 108). L'acquisizione di nuovo materiale documentario e la sua disamina, scevra da pregiudizi, consente invece, secondo Pierre Masson, di approfondire la conoscenza di entrambi gli autori e di far emergere le vere motivazioni alla base del loro reciproco cercarsi. 